производительности использования распараллеливания вычислений, можно решить в этой программной среде, реализовав необходимые библиотеки. ПОР является автоматизированной программной системой, которая использует весь потенциал подключенных к компьютеру вычислительных устройств, допускающих распараллеливание.

$$
* * *
$$

1. Камерон Х., Трейси. Х. Параллельное и распределенное программирование с использованием $\mathrm{C}++-$ М: Вильямс. - 2004. - 672 с.

2. Егоров А. Н., Марлей В. Е., Кузнецов В. А., Назаргулов И. А. Модель распараллеливания вычислений для повышения эффективности восстановления доступа к данным в корпоративных сетях // Труды СПИИРАН. - 2015. - № 5 (42). - С. 37-55.

3. Metaweia M. A., Ghoneim S. A., Haggag S. M., Nassar S. M. Load balancing in distributed multi-agent computing systems // Ain Shams Engineering Journal. - 2012. — Vol. 3. — Is. 3. — Pp. 237-249.

4. Daryapurkar A., Deshmukh M. V. M. Efficient Load Balancing Algorithm in Cloud Environment // International Journal Of Computer Science And Applications. — 2013. - Vol. 6. — No. 2. — Pp. 308-312.

\title{
Носков К.М. \\ Тенденции и развитие нейросетевых технологий в диагностике сложных систем
}

Нижегородский Государственный Технический Университет им. Р.Е. Алексеева (Россия, Нижний Новгород)

doi: $10.18411 / l j-31-08-2017-38$

idsp: 000001:lj-31-08-2017-38

\section{Аннотация}

Рассматривается вопрос диагностики сложных систем. Современные нейронные сети позволяют решать широкий круг задач. Наибольшее преимущество нейросетевые технологии получают в условиях априорной неопределенности, которая свойственна задачам диагностики трудноформализуемых систем.

Ключевые слова: нейронные сети, диагностика сложных систем

При создании сложных систем возникает необходимость их диагностики. Кроме общего состояния системы важно учитывать компоненты, из которых она состоит. Для решения задачи диагностики разрабатывают математические модели исследуемых систем, но в большинстве случаев такая задача является труднорешаемой из-за огромного количества нечетких параметров сложных систем и сложностью выявления закономерностей. Примером такой задачи может служить актуальная в настоящее время задача классификации биоценозов, решаемая совместно с ФБУН ННИИЭМ им. академика И.Н. Блохиной.

Искусственные нейронные сети представляют собой эффективный и гибкий метод имитации процессов и явлений и способны решать подобные задачи. Искусственная нейронная сеть подбирает скрытые внутренние параметры как отдельных нейронов, так и всей сети в целом, а также выделяет наиболее актуальные входные признаки и отбрасывает малоинформативные, некорректные признаки. Эта особенность позволяет нейронным сетям исправно работать с большим количеством неинформативных и избыточных данных.

Используя классические методы обработки данных иногда требуется запрограммировать вручную некоторые модели в символьном виде. Нейронная сеть конструируется указанием общей структуры и количеством входящих в ней элементов, а для её обучения необходимо предоставить достаточное количество тренировочных примеров. При наличии экспертных знаний по заданной задаче или по специальным требованиям нейронные сети позволяют подбирать нужный тип нейронов, структуру сети и задавать определенные характеристики. 
Нейронные сети имеют огромный потенциал в сфере параллельных вычислений. Нейроны одного слоя могут функционировать независимо друг от друга. Это позволяет ускорить процессы нейромоделирования и решать задачи реального времени.

Однако наряду с большим количеством положительных черт нейронных сетей существует ряд проблем при их использовании. Необходимостьвыбора типа сети[2], количества срытых слоёв и нейронов, от которых зависит эффективность нейронной сети и невозможность заранее определить сложность вычислительной сети, достаточную для решения поставленной задачи.

Несмотря на недостатки, нейронные сети являются перспективным средством диагностики сложных систем и в последнее время получают всё более широкое распространение.

\section{$* * *$}

1. Хливенко Л.В. Практика нейросетевого моделирования: монография / Л.В. Хливенко. - Воронеж: ФГБОУ ВО «Воронежский государственный технический университет», 2015. -214c. ISBN 978-5-7731$0429-2$

2. Горбачевская Е.Н. Классификация нейронных сетей. УДК 004.7 ББК 32.973.2 Журнал «Вестник Волжского университета им. В.Н. Татищева» 2012г

3. Ломакин Д.В., Пожидаева А.С., Блажнов И.Д. Модели и алгоритмы классификации состояний биоценозов на основе структурных свойств многомерных данных // Системы управления и информационные технологии, №3(61), 2015. - С. 22-27

\section{Щекочихин О.В. \\ Сервис-ориентированная архитектура как обеспечение расширения функций управления корпоративной информационной системы}

Костромской государственный университет

(Россия, Кострома)

doi: $10.18411 / l j-31-08-2017-39$

idsp: 000001:lj-31-08-2017-39

\section{Аннотация}

В работе рассматривается архитектуракорпоративной информационной системы на основе сервисов, интегрирующих в систему независимые приложения. Предложены методика построения информационной системы с сервис-ориентированной архитектурой, наделяющая ей свойством поведения.

Ключевые слова: корпоративная информационная система, интегрированная информационная система, модель поведения

Монолитные корпоративные информационные системы (КИС) обладают большой инерцией в плане расширения функциональных возможностей, что не позволяет оперативно реагировать на изменения в производственной системе. Одним из методов разрешения указанной проблемы является переход к интегрированным информационным системам (ИИС). Однако и в ИИС при расширении их функциональных возможностей имеют место такие ограничения как: необходимость фиксация структур данных, для обеспечения целостности; сложность в сопоставлении информационных ресурсов в разных системах метаданных; узкоспециализированные, частные решения; трудоемкость, а следовательно, высокая стоимость разработки, внедрения и владения.Для того чтобы снять выше указанные ограничения предлагается наделять информационную систему (ИС) свойством поведения. В данном случае под поведением ИС понимается её возможность в автоматическом или автоматизированном режиме добавлять или модифицировать её функции при неизменности её архитектуры[1]. 